\title{
Research of Electrical Discharge Machining Process of Wear Resistance Coatings Obtained By Beam Deposit Process
}

\author{
Timur Rizovich Ablyaz ${ }^{1}$, Vladimir Aleksandrovich Ivanov $^{1}$, Evgeniy Sergeevich Shlykov ${ }^{1}$, Evgeniy \\ Aleksandrovich Morozov ${ }^{1} \&$ Petr Viktorovich Maksimov ${ }^{1}$ \\ ${ }^{1}$ Perm national research polytechnic university, Perm, Russia \\ Correspondence: Timur Rizovich Ablyaz, Perm national research polytechnic university, 29 Komsomolsky \\ prospect, Building A, Office 208, Postcode 614990, Perm, Russia.
}

Received: December 15, 2014

Accepted: March 14, $2015 \quad$ Online Published: May 30, 2015

doi:10.5539/mas.v9n6p257

URL: http://dx.doi.org/10.5539/mas.v9n6p257

The study was financially supported by the Ministry of Education and Science of the Russian Federation by the state order (design part) No. 9.1570.2014/K.

\begin{abstract}
In modern mechanical engineering protective coatings are applied to improve the performance of the parts. The practical significance of the coatings is very high. External coating application can not only solve the problems for changing the physicochemical properties of the original surface, but also restore them after operation. Machining of such coatings on blade metalworking machines is often obstructing, and in combination with the small size of the reconstructed section of the part is impossible. Technologies of wire electrical discharge machining (WEDM) are applicable when machining parts of complex profile. This technology allows getting work pieces and parts of any type, regardless of their characteristics of resistance, without the use of additional tackle. Currently, the scientific basis of EDM process of reconstructed surface, the issues of accuracy and quality of treated surface of deposited machine parts are not fully explored. It is determined that the main factors affecting the formation of indicators of quality of machining of welded surface are the pulses characteristics $\left(\mathrm{t}_{\mathrm{on}}\right.$, $\left.t_{\text {off }}\right)$ and physicomechanical properties of the treated material. The developed model calculates the surface roughness in the process of EDM of wear resistant coatings produced by the beam deposition method depending on the cutting modes $\left(\mathrm{t}_{\mathrm{on}}, \mathrm{t}_{\mathrm{off}}\right)$ and physicomechanical properties of the material. Experimentally determined that in the wire electrical discharge machining process of U10 steel and welded material of 4H5MF1S steel with increasing electric power on the treated surface increases the thickness of the surface layer, wherein the microhardness of the layer is not changed. It is shown that in wire electrical discharge machining processing of steel U10 and welded material of 4H5MF1S steel shaped and modified surface layer does not affect the performance of produced parts.
\end{abstract}

Keywords: beam deposition, wire electrical discharge machining (WEDM), protective coating, surface layer

\section{Introduction}

The priority of modern mechanical engineering is the constant improvement of performance parameters of quality and reliability of manufactured products.

As noted in the study (Skhirtladze, \& Yarushin, 2006), the surface layer of the part has requirements which differ from requirements for the part as a whole. Surface hardening of the part, increase in hardness, wear resistance are obtained not only by the methods of thermochemical treatment and surface heat treatment, but also by the technology of pulsed laser deposition (PLD).

Pulsed laser deposition is an effective way to create a wear-resistant surface of machine parts and mechanisms (Gibson, et al., 2010).

Beam deposition process (BD process) enables the creation of coating material by melting and deposition of material from the source of feedstock material in powder form or wire feedstock on the finished base (Justin, 2006). Despite the fact that the method is implemented to operate with polymers, ceramics, and metal matrix composites, the method is most widely used for metal powders obtained. For heating the coating material, BD processes use energy focused into a narrow region (a beam). Energy is released by the focused heat source - the 
laser beam. Under the effect of the heat source, the feedstock material melts and the 3-dimentional objects build-up.

Further machining of parts with welded surface is an urgent task of mechanical engineering. When machining such parts, the minimum temperature heating of the deposited layer must be first ensured. Overheating can reduce the received physicomechanical characteristics of the deposited surface, which is not acceptable (Kunieda et all, 1998).

Machining of such parts is often impossible in the traditional metalworking equipment. In this regard, methods of electrical discharge machining (EDM) are widely used (Syanov, 2002).

Processes accompanying EDM are determined by physics of interaction of the material with a concentrated energy flux initiated by spark or pulsed arc discharge. Implementation of discharge is regulated by voltages applied to the electrodes, by the formation time of the pulse, by the state of the working fluid and by the magnitude of the interelectrode gap (Kinoshita, et al., 1984).

Currently, the scientific basis of EDM process of reconstructed surface, the issues of accuracy and quality of treated surface of deposited machine parts are not fully explored. At use of WEDM molybdenum or brass wire with a diameter of 0.02 to $0.3 \mathrm{~mm}$ is used as tool electrode, which makes it possible to machine to machining the deposited parts with high accuracy (Dauw, et al., 1989).

Existing mathematical calculation models of process parameters of EDM of wear resistant coatings produced by beam deposition are based either on empirical relationships or a particular simplified process model. At the same time there are no mathematical models allowing choosing the cutting mode for machining the recovered parts providing the desired accuracy rates.

The aim of the study is to improve the quality of the process of EDM of wear resistant coatings produced by beam deposition, by developing a methodology to calculate the theoretical and experimental performance surface quality.

\section{Methodology}

In the paper a theoretical and experimental study of the process quality of EDM of wear resistant coatings produced by beam deposition process is held.

Theoretical modeling is used to create a mathematical model of the formation process of surface roughness.

Experimental studies to test the model roughness were held using the method of classical experiment.

Studies designed to test mathematical models are held by the following algorithm:

1. The analysis of mathematical models identifies factors that influence the determining parameters of quality of the treated surface.

2. Of all the identified factors, one is selected which is sequentially changed during the experiment, the determined quality parameters will be measured after. However, the other factors remain unchanged. The sample size according to the nomogram of sufficiently large numbers at the value of the probability $\mathrm{P}=0.95$ equals 6 (Losev, 1985).

3. Similarly to claim 2, the defined quality index is calculated, varying the selected factor and using mathematical models.

4. With the Student's coefficient the experimental results are compared with the results obtained from the calculation of mathematical models.

As an experimental sample the square section work piece is selected, it is made of U10 steel according to GOST 14959-70. Work piece thickness is $0.01 \mathrm{~m}$. Steel 4H5MF1S to GOST 5950-2000 is chosen as the material for deposition. The height of the deposited layer is $0.003 \mathrm{~m}$.

Beam deposition LENS 850R (Laser Engineered Net Shaping) machine installation was obtained for the application of the deposited layer. Modes are selected according to the recommendations of Systemmanual OPTOMECLENS 850-R. During beam deposition, the laser creates a molten bath (generally, $0.25-1 \mathrm{~mm}$ in diameter and 0.1-0.5 mm in depth) on the bottom, into which a powder is entered. Upon entering the molten bath, the powder particles melt and solidify. Small molten bath and fast speed of relative movement of the laser allows obtaining high rates of cooling and large temperature gradients. Depending on the material, or the deposited alloy, high rates of cooling give rise to unique grain structures, and therefore, the deposited coatings have high physicomechanical properties (Justin, 2006). 
A wire EDM EcoCut is used for processing the samples.

Brass Bercocut EDM Wire of $0.25 \mathrm{~mm}$ in diameter is used as the electrode tool. Distilled water is selected as the working fluid.

Metallographic analysis was conducted to study the influence of processing conditions on a change in the surface layer of the processed work pieces.

4 substrates with different modes of deposition with 3 samples for each mode were chosen for the experiment. Each sample was processed at a certain mode. Processing modes are shown in Table 1.

Table 1. Machining modes

\begin{tabular}{lccc}
\hline \multicolumn{1}{c}{ Modes } & max & med & min \\
\hline Pulse on time period $\left(\mathrm{t}_{\text {on }}\right), \mathrm{ms}$ & 21 & 10 & 1 \\
Pulse on time period $\left(\mathrm{t}_{\text {off }}\right), \mathrm{ms}$ & 60 & 30 & 30 \\
Voltage $(\mathrm{U}), \mathrm{V}$ & 50 & 50 & 50 \\
Electric power $(\mathrm{I}), \mathrm{A}$ & 2.5 & 1.5 & 1 \\
\hline
\end{tabular}

During the experiment the physical characteristics of the cutting for each mode have been removed with the sensors of the machine: voltage (U), V; electric power (I), A; cutting speed (V), $\mathrm{mm} / \mathrm{min}$. Table 2 shows the characteristics of the cutting removed from the sensors.

Table 2. Physical characteristics of the cutting

\begin{tabular}{ccccc}
\hline \# sample & Max & Med & Min \\
\hline 1 & $\mathrm{U}=50 \mathrm{~V}$ I=2.5 A & $\mathrm{U}=50 \mathrm{~V} \quad \mathrm{I}=1.5 \mathrm{~A}$ & $\mathrm{U}=50 \mathrm{~V} \mathrm{I}=1 \mathrm{~A}$ \\
& $\mathrm{~V}=1 \mathrm{~mm} / \mathrm{s}$ & $\mathrm{V}=0.5 \mathrm{~mm} / \mathrm{s}$ & $\mathrm{V}=0.3 \mathrm{~mm} / \mathrm{s}$ \\
2 & $\mathrm{U}=50 \mathrm{~V} \mathrm{I}=2.5 \mathrm{~A}$ & $\mathrm{U}=50 \mathrm{~V} \mathrm{I}=1.5 \mathrm{~A}$ & $\mathrm{U}=50 \mathrm{~V} \mathrm{I}=1 \mathrm{~A}$ \\
& $\mathrm{~V}=1 \mathrm{~mm} / \mathrm{s}$ & $\mathrm{V}=0.5 \mathrm{~mm} / \mathrm{s}$ & $\mathrm{V}=0.3 \mathrm{~mm} / \mathrm{s}$ \\
3 & $\mathrm{U}=50 \mathrm{~V} \mathrm{I}=2.5 \mathrm{~A}$ & $\mathrm{U}=50 \mathrm{~V} \mathrm{I}=1.5 \mathrm{~A}$ & $\mathrm{U}=50 \mathrm{~V} \mathrm{I}=1 \mathrm{~A}$ \\
& $\mathrm{~V}=1 \mathrm{~mm} / \mathrm{s}$ & $\mathrm{V}=1 \mathrm{~mm} / \mathrm{s}$ & $\mathrm{V}=0.3 \mathrm{~mm} / \mathrm{s}$ \\
4 & $\mathrm{U}=50 \mathrm{~V} \mathrm{I}=2.5 \mathrm{~A}$ & $\mathrm{U}=50 \mathrm{~V} \quad \mathrm{I}=1.5 \mathrm{~A}$ & $\mathrm{U}=50 \mathrm{~V} \mathrm{I}=1 \mathrm{~A}$ \\
& $\mathrm{~V}=1 \mathrm{~mm} / \mathrm{s}$ & $\mathrm{V}=1 \mathrm{~mm} / \mathrm{s}$ & $\mathrm{V}=0.3 \mathrm{~mm} / \mathrm{s}$ \\
\hline
\end{tabular}

Metallographic analysis of the work piece surface after EDM was performed using light microscope Olympus GX 51 with 500-fold magnification. Microsections were consistently ground off on coated abrasives. The polished sample surface was etched with $4 \%$ nitric acid in ethanol. The interaction between the metal surface and a reagent selective dissolution of areas occurs due to their differences in physicochemical properties. The most heavily etched are defective parts - the grain and interphase boundaries. As a result, microtopography is formed on the microsection surface. Stronger dissolve areas of microsection perceived as dark and undissovle as light under the microscope.

Measurement of roughness of treated surface were conducted on profilometer Mahr Perthometer S2 according to GOST 2789-73.

\section{Results}

\subsection{Results of Model Formation of Surface Roughness in Wire Electrical Discharge Machining of Reconditioned Parts}

According to the concepts of the formatting surface roughness, geometrically, roughness is formed by combining the geometry of the cutting part of the tool and the serve (Solomentsev, et al., 1980). In the process of EDM material machining is done by the current pulse which leaves of a single pit on the work piece surface. The final form of the microrelief is a superposition of the pits at each other. Roughness parameter Ra is defined by the formula (Dauw, et al., 1989):

$$
R a=\frac{1}{l} \int_{0}^{l} y(x) d x,
$$

where 1 - base length for determining the surface roughness (m); $y$ - variation of profile from the line $(\mathrm{m})$.

During the process of wire electrical discharge machining, tool electrode is fixed vertically relative to the electrode-part and it moves in the direction of serve with the speed of $\mathrm{Q}_{\mathrm{s}}(\mathrm{m} / \mathrm{s})$. 
Since electrode wire has a small diameter $(0.3$ to $0.03 \mathrm{~mm})$ in cross section, it is subject to intensive wear. As a result of electrode wear, roughness of treated welded surface is formed unequally. However, due to the fact that during machining electrode wire continuously unwound with a certain speed of $V_{\text {wire }}(\mathrm{m} / \mathrm{min})$, the wear effect on the value of roughness becomes negligible.

Modeling is aimed at obtaining the equation, which establishes the relationship between the influence of the modes of electrical discharge machining and deposited material on the value of roughness of the treated surface.

In calculating roughness of the treated deposited surface, the thermal model and methodology proposed in the study (Syanov, 2002) is used, it is based on the fact that energy of one working pulse, taking into account the coefficient of efficiency of using a pulse, equals to the thermal energy, which is necessary to inform to the mass of the material for its heating, melting and evaporation from the workpiece surface. Thus:

$$
\begin{gathered}
c \\
\left(s \Delta T_{m}+\lambda_{m}+c_{l} \Delta T_{l}+r\right), \\
\eta_{p} \cdot U \cdot I \cdot t_{p}=m
\end{gathered}
$$

The weight of the removed material is expressed as the multiplication of the volume of metal removed by its density:

$$
m=V \cdot \rho,
$$

where $\mathrm{V}$ - the volume of the removed material $\left(\mathrm{m}^{3}\right) ; \rho$ - the density of the material $\left(\mathrm{kg} / \mathrm{m}^{3}\right)$.

Substituting the expression (3.3) in (3.2) the value of the volume of the removed material per working pulse is determined:

$$
\begin{gathered}
c \\
\left(s \Delta T_{m}+\lambda_{m}+c_{l} \Delta T_{l}+r\right) \cdot \rho, \\
V=\underline{\eta_{p} \cdot U \cdot I \cdot t_{p}}
\end{gathered}
$$

It is determined (Syanov, 2002) that the form a single pit is close to spherical, so that its volume corresponding to the volume of the removed metal is defined as the volume of a spherical segment,

$$
V=\frac{1}{3} \cdot\left(\pi \cdot h_{p}^{2} \cdot\left(3 \cdot R-h_{p}\right)\right),
$$

where $\mathrm{R}$ - the radius of arbitrary sphere (m); $h_{p}$ - the depth of the single pit (m).

Connection of the radius of arbitrary sphere with the value of the coefficient of overlapping and the depth of the single pit is represented in the study (Syanov, 2002). Using this methodology and the conditions that the size of the resulting pits are equal, we receive:

$$
R=\frac{2 \cdot \beta}{2 \cdot \beta-1} \cdot h_{p},
$$

where $\beta$ - the coefficient of overlapping pits.

Thus, substituting the equation (3.6) in (3.5) and equating with (3.4), the depth of the pit is expressed:

$$
\begin{gathered}
{ }^{c} \cdot U \cdot I \cdot t_{p} \cdot(6 \cdot \beta-3) \\
\left(s \Delta T_{m}+\lambda_{m}+c_{l} \Delta T_{l}+r\right) \cdot \rho \cdot \pi \cdot(4 \cdot \beta+1)
\end{gathered}
$$

With the assumption that in the machining process the wear of wire is compensated by the speed of its winding, the sizes of pits are equal and the coefficient of overlapping has a constant value equal to $\beta=1.2$, therefore, it can be argued that the theoretical profile of microasperity remains unchanged at the base length. Thus, the expression (3.2) is written:

$$
R a=\frac{1}{\mathrm{M}^{\prime}} \sum_{i=1}^{n} C_{i}
$$

where the length $l \geq \mathrm{M}^{\prime}(\mathrm{m}) ; \mathrm{C}_{\mathrm{i}}$ - the area of elementary figure $\left(\mathrm{m}^{2}\right) ; \mathrm{n}$ - the number of elementary figures within the $S^{\prime}$. 
Based on the assumption of the constant size of pits, their number $\mathrm{n}$ on the length of $S^{\prime}$ is defined as the ratio of $\mathrm{M}^{\prime} / \mathrm{d}_{\mathrm{p}}$ (Figure 1).

It is proved (Syanov, 2002) that the diameter of the pit is related to the depth $h_{p}$ expression:

$$
d_{p}=h_{p} \cdot \sqrt{\frac{8 \cdot \beta+4}{2 \cdot \beta-1}},
$$

The single pit is a spherical segment; therefore, its area is calculated:

$$
C=\pi \cdot h_{p} \cdot d_{p}
$$

Substituting the expression (3.9) in (3.10) can calculate the value of roughness of treated surface on the predetermined length;

$$
\begin{aligned}
& \begin{array}{c}
c \\
\left(s \Delta T_{m}+\lambda_{m}+c_{l} \Delta T_{l}+r\right) \cdot \rho \cdot \pi \cdot(4 \cdot \beta+1)
\end{array} \\
& \underline{\eta_{p} \cdot U \cdot I \cdot t_{p} \cdot(6 \cdot \beta-3)} \\
& \frac{2}{3} \text {. } \\
& \pi \text {. } \\
& R a=\frac{1}{\mathrm{M}^{\prime}} \sum_{i=1}^{n}
\end{aligned}
$$

Analyzing the expression (3.11) shows that roughness of deposited surface directly depends on the processing modes. By increasing the duration of the pulse and electric power, roughness of treated surface increases. Reducing the pulse energy tends to reduce the value of surface roughness. This model allows calculating the value of the roughness in the machining of wear resistant surface produced by the beam deposition process in wire electrical discharge machine.

\begin{tabular}{|c|c|c|c|}
\hline \# sample & Ra on max mode, $\mu \mathrm{m}$ & Ra on med mode, $\mu \mathrm{m}$ & $\mathrm{Ra}$ on $\min$ mode, $\mu \mathrm{m}$ \\
\hline \multirow[t]{2}{*}{1} & Ra.p $=1.9$ & Ra.p $=1.7$ & Ra. $p=1.5$ \\
\hline & Ra.d $=2.5$ & Ra.d=2.1 & Ra.d=1.9 \\
\hline \multirow[t]{2}{*}{2} & Ra. $p=2.1$ & Ra. $p=1.8$ & Ra.p $=1.7$ \\
\hline & Ra.d $=2.5$ & Ra.d $=2.4$ & Ra.d $=2.3$ \\
\hline \multirow[t]{2}{*}{3} & Ra.p $=1.8$ & Ra.p $p=1.6$ & Ra. $p=1.5$ \\
\hline & Ra.d $=2.4$ & Ra. $d=2.3$ & Ra. $d=2.0$ \\
\hline \multirow[t]{2}{*}{4} & Ra.p $=1.9$ & Ra. $p=1.8$ & Ra.p $p=1.7$ \\
\hline & Ra.d $=3.8$ & Ra. $d=4.5$ & Ra. $d=4.2$ \\
\hline
\end{tabular}

\subsection{Checking the Adequate Mathematical Model}

In order to verify the adequacy of the cut samples, surface roughness (Ra) was measured. Roughness values for different machining modes are presented in Table 3, where Ra.p, $\mu \mathrm{m}$ - roughness of the part, Ra.d, $\mu \mathrm{m}-$ roughness of the deposited area. Table 3 shows the values of surface roughness of, depending on the machining modes.

Table 3. Surface roughness depending on the machining modes

The pulse time $t_{p}(s)$ with the treated material is chosen as a parameter for the variation in the experiment.

Data obtained from the experiment and the calculation of the mathematical model is presented in Table 6 .

Comparing the calculated and experimental values of the correction, it is seen that the difference does not exceed $15 \%$.

The calculation of the standard deviation for each group of data is done by the formula:

$$
\sigma=\frac{X_{\max }-X_{\min }}{K}
$$

where $\mathrm{K}$ - tabular coefficient, $\mathrm{K}=2.53, X_{\max }, X_{\min }$ - the largest and the smallest values of the considered quantity in each group.

$$
\text { Thus } \sigma_{\text {exper }}=\sigma_{\text {calc }}=0.002 \text {. }
$$


The standard error of mean value is equal to:

$$
m=\frac{\sigma}{\sqrt{n-1}}
$$

For the experimental and calculated values $\mathrm{m}=0.001$.

The average error of the difference is calculated:

$$
t=\frac{\overline{X_{\text {exper }}}-\overline{X_{\text {calc }}}}{\sqrt{m_{\text {exper }}^{2}+m_{\text {calc }}^{2}}},
$$

Table 4. Variation of experimental and calculated data

\begin{tabular}{llll}
\hline Material & Time period $\mathrm{t}_{\mathrm{p}}, \mathrm{s}$ & Value of $\mathrm{Ra}_{\text {exper }}, \mu \mathrm{m}$ & Value of $\mathrm{Ra}_{\text {calc }}, \mu \mathrm{m}$ \\
\hline U10 & 0.000030 & 1.9 & 2.4 \\
U10 & 0.000025 & 1.7 & 1.9 \\
U10 & 0.000021 & 1.5 & 2.2 \\
4H5MF1S & 0.000030 & 2.5 & 2.9 \\
4H5MF1S & 0.000025 & 2.1 & 2.5 \\
4H5MF1S & 0.000021 & 1.9 & 2.3 \\
Mean $(\bar{X}$ & & 1.9 & 2.4 \\
\hline
\end{tabular}

The standard deviation for each group of data equals: $\sigma_{\text {exper }}=0.23, \sigma_{\text {calc }}=0.25$.

The standard error of mean value for each group of data equals: $m_{\text {exper }}=0.16, \sigma_{\text {calc }}=0.14$.

The estimated value of the Student's coefficient equals: $t=2.1$. Tabular value of the Student's coefficient for a given number of degrees of freedom equals: $t_{\text {tabul }}=2.5$. Since the calculated coefficient is less than tabular, the mathematical model can be considered adequate.

\subsection{Metallographic Analysis}

Conducting metallographic analysis shows that the surface layer of steel and deposition after EDM with maximum mode (Figure 1) qualitatively and quantitatively differ from the surface layer after machining with minimal mode (Figure 3). It was established that the machining in maximum mode surface layer is deeper, and there are loose buildups on surface. This layer covers the entire surface, and breakdown and violations are almost not observed. In the case of minimum mode surface layer has frequent breakdowns on depth exceeding the layer, and the layer itself looks equable on thickness without expressed loose buildups. The conducted study shows that the hardness is not changed.

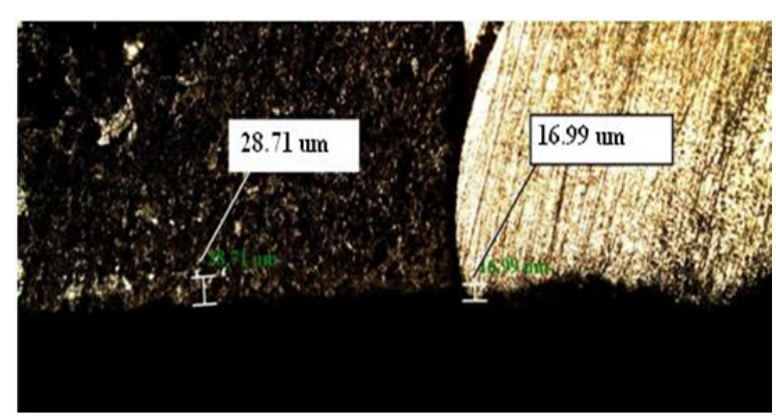

Figure 1. Surface layer while machining at maximum

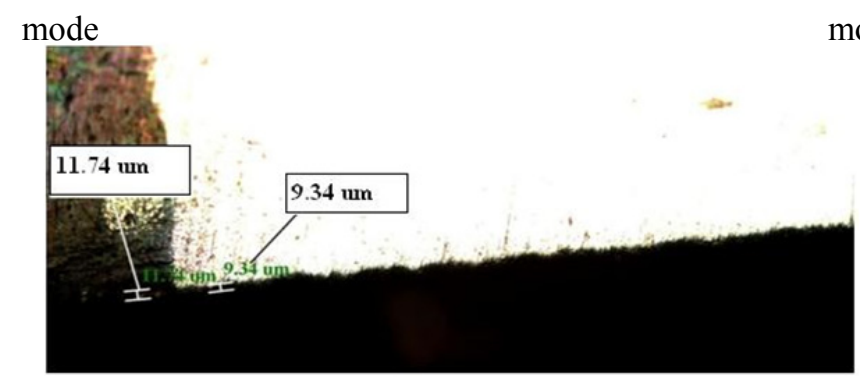

Figure 3. Surface layer while machining at minimum mode

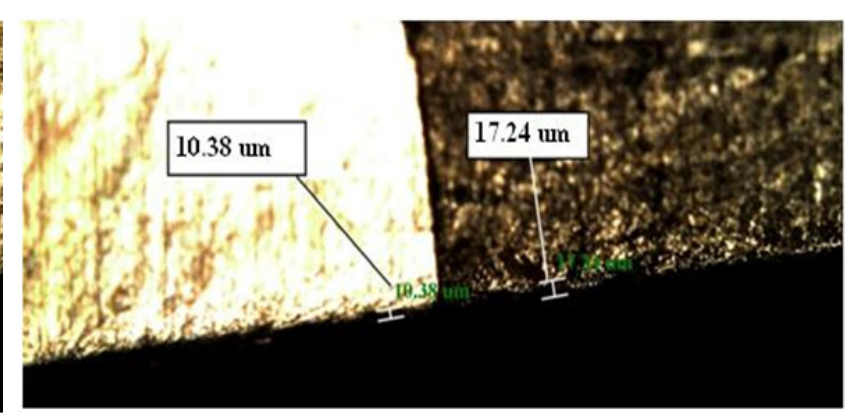

Figure 2. Surface layer while machining at medium mode 
According to the results of metallographic studies, the conclusion is that the maximum depth of the surface layer on the area of U10 steel and deposited material was achieved in case the maximum mode. Since it was established (Kabaldin, et al., 2007) that the surface layer represents a defect structure, the development of technology requires to select the modes in which its value is minimal. However, when operating at minimal cutting modes performance of machining decreases. The study found that machining at the average mode will provide the optimal ratio between the depth of the surface layer and performance.

\section{Discussion}

Surface roughness has a significant influence on the performance of the parts (Syanov, 2002). After EDM, surface ED has roughness which is formed by a large number of mutually intersecting pits (Tarng, 1995). Surface roughness depends on the pulse energy and properties of the treated material and calculated (Foteev, 1994):

$$
R z=\frac{\beta^{2}}{3} k_{4} \sqrt[3]{W_{p}}
$$

where $\beta$-coefficient of overlapping pites (for maximum roughness $\beta=1.2$ ); $\mathrm{k}_{4}$ - constant value that does not depend on the duration and the pulse energy; $\mathrm{W}_{\mathrm{p}}$ - pulse energy $(\mathrm{J})$.

With increasing pulse energy $\mathrm{W}_{\mathrm{p}}$ roughness of treated surface increases. This is due to the fact that with increasing of $\mathrm{W}_{\mathrm{p}}$ more heat is allocated during a single pulse, thus, there is greater deposition of metal, which in turn leads to an increase in the radius of pit $r_{p}$, and, as a result, the coefficient of overlapping $\beta$. Thus, for smaller values of the roughness parameters it is necessary to select the machining mode properly.

Currently, there are several models for the calculation of the surface roughness after EDM. However, most of them are based only on theoretical dependence and are not applied in practice. In the paper (Serebrenitsky, 2007) the method of geometric constructions in view of the coefficient of overlapping pits was used to determine the maximum height of roughness of profile. Thus, the formula for calculating the maximum surface roughness is represented as:

$$
R \max =\frac{\beta^{2} \cdot h_{p} \cdot r_{p}^{2}}{r_{p}^{2}+h_{p}^{2}},
$$

where $h_{p}$ - the depth of the pit (m); $r_{p}$ - radius of the pit (m); $\beta$ - coefficient of overlapping pits.

When calculating surface roughness of the formula (4.2), the intersection of three equal-sized spheres is the base. From each area was considered part simulating the shape of a single pit. When calculating the roughness parameters, machining modes, the composition of the working fluid and the tool wear are not considered (Spedding, 1997).

In the studies (Jurin, 2005) the calculation of surface roughness is made by using empirical relationships. These dependences characterize the influence of the pulse energy and duration of the pulses on the value of roughness $\mathrm{Rz}$, which is calculated by the formula:

$$
R z=\alpha \cdot W_{p}^{b},
$$

where $\alpha$ - the coefficient depending on the properties of the treated material, the material of the electrode tool and properties of the working fluid; $b$ - the index for the calculations, taken equal to 0.33 .

Analyzing the considered models of calculation of the roughness parameters, it can be said that these models are purely theoretical in nature and cannot find a practical use because of the impossibility of their calculation, due to lack of data.

The paper gives the equations for the calculation of roughness parameters, based on the size of single pits. Thus, knowing the radius and depth of the pits, it becomes possible to determine the roughness parameters. However, the calculation equations of the size of the pits are not given. Furthermore, the models are not considered relationship between the size of roughness of the treated surface and machining modes.

In this paper, the mathematical model is obtained which allows calculations: the roughness of the treated surface. The model allows calculating the roughness on the specified parameters: the physical properties of the treated material and pulse parameters.

It is found (Ablyaz, et al. 2012) that the properties of the surface layer change significantly as a result EDM. The properties of this layer are not fully defined. 
Because of the fragility and unequal density in some cases, the surface layer is defective. It reduces the strength properties of the base metal, since the mechanical, especially alternating, loads it easily cracks occur which may extend deep into the parts (Rajurkar \& Wang, 1993). Therefore, in the manufacturing of parts, designed for use with heavy loads, usually it requires to remove the modified layer by one of ways of finishing machining or use more modern electrical discharge technologies and related equipment (Scott et al., 1991).

Analysis of experimental data shows that the process of electrical discharge machining of U10 steel does not depend on the hardness of the surface layer of the treated material 4H5MF1S (Liao, et al., 1997).

According to metallographic analysis, the depth of the surface layer does not depend on the hardness of the treated work piece, and not exceed $30 \mu \mathrm{m}$ (Artamonov \& Volkov, 1991). The work found that the resulting structural changes of the surface layer after EDM are not significant and do not affect the performance of the finished part.

\section{Conclusion}

On the basis of the conducted research of the EDM process of wear resistant surface produced by beam deposition, it was found that one of the main indicators of quality of the machining surface are roughness, the structure of the surface layer. It is found that the main factors affecting the formation of indicators of quality of machining of welded surface are the parameters of pulses $\left(\mathrm{t}_{\mathrm{on}}, \mathrm{t}_{\mathrm{off}}\right)$ and physicomechanical properties of the treated material.

The developed model allows calculating roughness of the surface finish in EDM process of wear resistant coatings produced by beam deposition depending on the cutting modes $\left(t_{\text {on }}, t_{\text {off }}\right)$ and physicomechanical properties of the material. It is found that with increasing pulse energy increases the roughness of the machined surface. By increasing the mode from $\min \mathrm{t}_{\mathrm{on}}=1 \mathrm{~ms}, \mathrm{t}_{\text {off }}=30 \mathrm{~ms}$ to $\max \mathrm{t}_{\mathrm{on}}=21 \mathrm{~ms}, \mathrm{t}_{\text {off }}=60 \mathrm{~ms}$ roughness changed from $\mathrm{Ra}=1.5 \mu \mathrm{m}$ to $\mathrm{Ra}=1.9 \mu \mathrm{m}$.

The study found that wire electrical discharge machining, in the studied range of cutting conditions, has no effect on the structural changes in the surface layer of the work pieces. It is shown that in wire electrical discharge machining of U10 steel and deposited material of 4H5MF1S steel shaped and modified surface layer does not affect the performance of finished parts. This type of machining is used for work pieces of U10 steel with hardened surface layer of 4H5MF1S steel.

Since this study of quality indicators and performance was held for only one material of U10 steel and material of deposition 4H5MF1S, the process of EDM of wear resistant coatings produced by beam deposition cannot be considered as fully studied in this paper. Based on the results of the conducted research. It is possible to develop the technology of EDM of wear resistant coatings produced by beam deposition process in the future.

In the further work the increase in the nomenclature of studied materials is planned. On the basis of the received data mathematical models by factor calculation of coefficient of metal remove are developed at processing directed surfaces.

The obtained data is presented in the form of typical technology and takes root at the leading machine-building enterprises of the Perm krai.

\section{References}

Ablyaz, T., Khanov, A., \& Hurmatullin, O. (2012). Modern approaches to the technology of electrical discharge machining of materials. Perm: Perm national research polytechnic university, University Press.

Artamonov, B., \& Volkov, Y. (1991). Analysis of models of processes of electrochemical and electrical machining. Ch.2. Models of processes of EDM. Wire cutting. Moscow: VNIIPI.

Dauw, D., Sthioul, H., Delpretti, R., \& Tricarico, C. (1989). Wire analysis and control for precision EDM cutting. Ann. CIRP-38, 1, 191-194.

Foteev, N. (1994). Quality control of technological surface tooling at electro erosion processing. Electron material processing, 2, 5-7.

Gibson, I., Rosen, D., \& Stucker, B. (2010). Additive Manufacturing Technologies: rapid prototype into direct digital manufacturing. Ch. 9. New York: Springer. ISBN 978-1-4419-1119-3.

Jurin, A. (2005). Methods of calculation of technological parameters and tool electrode in EDM process. Dissertation. Tula: TSU.

Justin, D., \& Stucker, B. (2006). Improving implants using laser-based metal deposition technologies. BONEZone. 
Kabaldin, G., Sarilov, M., \& Bilenko S. (2007). Improving the sustainability of the process of electrical discharge machining and quality of treated surface based on artificial intelligence approaches. Komsomolsk-on-Amur: KnAGTU.

Kinoshita, N., Fukui, M., \& Kimura, Y. (1984). Study on wire-EDM: in process measurement of mechanical behavior of electrode-wire. Ann. CIRP-33, 1, 89-92.

Kunieda, M., Takeshita, S., \& Okumiya, K. (1998). Study on wire electrode temperature in WEDM. Proceedings of international Symposium for Electromachining - ISEM XII, 151-161

Liao, Y., Huang, J., \& Su, H. (1997). A study on the machining-parameters optimization of wire electrical discharge machining. J. Mater. Process. Technol., 71, 487-493.

Losev, V. (1985). Multi-factorial experiment planning. Perm.

Rajurkar, K., \& Wang, W. (1993). Thermal modeling and on-line monitoring of wire-EDM. J. Mater. Process. Technol., 1-2(38), 417-430.

Scott, D., Boyina, S., \& Rajurkar, K. (1991). Analysis and optimization of parameter combination in wire electrical discharge machining. Int. J. Prod. Res., 29(11), 2189-2207.

Serebrenitsky, P. (2007). Electro-technology and modern equipment: Tutorial. St. Petersburg: Baltic state technical university.

Skhirtladze, A., \& Yarushin, S. (2006). Technological processes in mechanical engineering: Textbook. 2nd ed., revised and updated. Perm: Perm state technical university.

Solomentsev, Y., \& Mitrofanov, V. et al. (1980). Adaptive control of technological processes. Moscow: Mechanical Engineering.

Spedding, T., \& Wang, Z. (1997). Parametric optimization and surface characterization of wire electrical discharge machining process. Precis. Eng., 20(1), 5.

Syanov, S. (2002). Technological support of surface layer quality of parts at EDM processing: Dissertation. Bryansk: BGTU.

Tarng, Y., Ma, S., \& Chung, L. (1995). Determination of optimal cutting parameters in wire electrical discharge machining. Int. J. Mach. Tools Manuf., 35(129), 1693-1701.

\section{Copyrights}

Copyright for this article is retained by the author(s), with first publication rights granted to the journal.

This is an open-access article distributed under the terms and conditions of the Creative Commons Attribution license (http://creativecommons.org/licenses/by/3.0/). 